\title{
Biomass and Algal Oil Productivity with Fatty Acid Profiles of Botryococcus Sp. Cultures Under Different Concentrations of Nitrogen
}

\author{
Erly Marwani* and Ivana Kurniawan \\ School of Life Sciences and Technology, Institut Teknologi Bandung, Jl. Ganesha No. 10 Bandung, Indonesia; \\ erly@sith.itb.ac.id, ivana.kurniawan.18@gmail.com
}

\begin{abstract}
Objectives: To develop an efficient Botryococcus sp. for high biomass and oil productivity with a fatty acid profile suitable for biodiesel. Methods and analysis: The culture of Botryococcus sp.was maintained in the modified Chu-13 medium at 16:8 light and dark cycle with 5,200 lux light intensity at $25^{\circ} \mathrm{C}$ and aerated with $1.5 \mathrm{~L}$ of air per minute. The nitrogen concentrations of the media varied, 5, 28, 55 (control), $350 \mathrm{mg} \mathrm{L}^{-1}$, with a constant concentration of phosphorous (44 mg $\mathrm{L}^{-1}$ ). For growth determination, Botryococcus sp. was harvested, dried, and weighed. Nitrogen consumption was measured by spectrophotometric methods. Oil was extracted from dried biomass of the algae using a soxhlet extractor $\left(70^{\circ} \mathrm{C}, 4\right.$ hours), followed by methylation and analysis of fatty acids using gas chromatography. Findings: The results under these sets of experiments indicated that $350 \mathrm{mg} \mathrm{N} \mathrm{L}^{-1}$ gave the maximal growth rate i.e. $0.24 \mathrm{~g} \mathrm{day}^{-1}$ and the maximal biomass productivity i.e. $77.5 \mathrm{mg} \mathrm{L}^{-1} \mathrm{day}^{-1}$. On the other hand, the maximal oil productivity of $5.03 \pm 0.10 \mathrm{mg} \mathrm{L}^{-1} \mathrm{~d}^{-1}$ was obtained from medium containing nitrogen $55 \mathrm{mgL}^{-1}$. The fatty acid profile of Botryococcus sp. oil showed a high amount of palmitic acid and oleic acid. Nitrogen concentrations of 5, 28, 55 (control) and $350 \mathrm{mg} \mathrm{L}^{-1}$ in the culture media resulted in $38.07 \%$, 34.59\%, 29.48\%, 19.43\% palmitic acid and 22.29\%, 24.52\%, 26.99\%, 8.81\% oleic acids respectively. These fatty acid profiles indicated that the Botryococcus sp. oil could be processed into biodiesel. Novelty: Growth, oil biomass content and fatty acid profiles of Botryococcus sp. cultures were affected by nitrogen concentration of the media. In this study, 55 mg N L${ }^{-1}$ was the most efficient nitrogen concentration for maximal oil productivity with fatty acid content that met the requirements for conversion into biodiesel.
\end{abstract}

Keywords: Botryococcus Sp., Algal Oil, Fatty Acid, Nitrogen

\section{Introduction}

Biodiesel is one of the alternative fuels obtained by transesterification of triglyceride oil by monohydric alcohols. 1 Triglyceride (TAG) oil can be obtained from biomass of many algae, both micro and macro algae, which had been reported to have promising potential as renewable energy sources for biodiesel production. 2 That potential was indicated by the high lipid content of a number of algae that could be converted into biodiesel by the process of transesterification. $\underline{3}$

Most algae are aquatic species that can be found easily either in marine or freshwater habitats. Among the freshwater microalgae, Botryococcus braunii had been reported to contain high amount of lipids and longchain hydrocarbons. ${ }^{4}$ Botryococcus sp.is a photosynthetic unicellular microalgae which belongs to the Chlorophyta division and can be found in all continents with various environmental conditions. $\frac{4}{}$ Botryococcus braunii can contain lipid $25-75 \%$ of its biomass dry weight ${ }^{\underline{5}}$ with productivity up to $190 \mathrm{mg} \mathrm{L}^{-1}$ day $^{-1} .6$ The hydrocarbon composition of Botryococcus braunii becomes a distinct advantage in the manufacture of high-quality biodiesel because it has a high proportion of oleic acid, which is $50 \%$ of total fatty acids, $\underline{6}$ and is dominated by saturated fatty acids and monounsaturated fatty acids. $\underline{7}$

${ }^{*}$ Author for correspondence 
Botryococcus sp. can be cultivated both in open or closed systems. Cultivation in an open system is rather an uncontrolled situation since physical factors such as light; temperature and rainfall fluctuate depending on the season. Temperature fluctuation and light limitation could cause low biomass productivity. .99 As well as the physical factors, the chemical factors such as nutrients in an open-air system can vary depending on where and when the algae cultivation is carried out (depends on climate conditions, $\mathrm{pH}$, light and other culture conditions). Cultivation in a closed system is certainly more controllable; therefore it could overcome problems of an open-air system. Yet, photobioreactor is recognized as the most suitable system for regulating algal culture conditions for better growth and it produces more hydrocarbon oil so that an increase in biomass (growth) and hydrocarbon production can be obtained. However, the cultivation of algae in a closed system has significantly higher energy requirements and also greater capital costs investments. $\frac{10}{}$ Therefore, it is necessary to calculate the efficient amount of nutrients needed to be added for maximum productivity yield.

Cultivation and hydrocarbon oil production in Botryococcus sp. are affected by internal factors (microalgae strain) and also external factors such as temperature, $\mathrm{pH}$, salinity, light, and nutrient composition in the medium. Among the factors, nitrogen is the most important macronutrient which composes $7-20 \%$ of the biomass dry weight, $\underline{\underline{11}}$ which is used in building cellular components such as proteins, amino acids, nucleic acids, and chlorophyll. In general, nitrogen can be added in the form of $\mathrm{NO}_{3}^{-}, \mathrm{NH}_{4}{ }^{+}$, or other organic forms. 12 Botryococcus sp. has been known to grow better with nitrogen in the form of nitrate, especially potassium nitrate. $\underline{13}$ Furthermore, various studies have shown the accumulation of triacylglycerol (TAG) in cultures increased under nitrogen deficiency conditions. Nitrogen deficiency in the culture may cause an increase of TAG synthesis from acyl-CoA on the de novo pathway, recycling a portion of acyl from the degradation of hydrocarbon membrane to TAG; and increasing carbon flow to glycerol-3-phosphate (G3P) and acyl CoA which are used in fatty acid synthesis. $\underline{14}$

For setting up the microalgae culture system of Botryococcus sp. in a controlled culture system that can produce hydrocarbon oil in the optimum amount, different initial nitrate concentrations in the culture media was studied to determine the most efficient nitrogen concentration for high biomass growth and accumulation of algal oil with fatty acid profiles that are suitable for conversion to biodiesel. Therefore, in this study, we report the growth of Botryococcus sp. and nitrogen consumption in the medium, level of oil accumulation, and fatty acid profile in cells of Botryococcus sp. Through this study, the most efficient nitrogen concentration that supports Botryococcus sp. biomass growth and efficient nitrogen level for obtaining high oil productivity with a fatty acid profile suitable for conversion into biodiesel would be determined.

\section{Materials and Methods}

The scope of the study includes cultivation of Botryococcus sp. cultivation in different concentrations of nitrogen, harvesting cells for determination of growth and growth kinetics, measuring nitrogen consumption in the media, oil extraction and quantification, and fatty acid profile determination.

\subsection{Cultivation of Botryococcus sp.}

The microalga was collected from the Aquaculture Development Centre (ADC), West Java, Indonesia. Based on morphological characteristics, the microalgae obtained from ADC was identified as Botryococcus sp. The microalgae were maintained in $1.0 \mathrm{~L}$ modified $\mathrm{Chu}-$ 13 medium which was composed of $\mathrm{KNO}_{3}, \mathrm{~K}_{2} \mathrm{HPO}_{4}$, $\mathrm{MgSO}_{4} \cdot 7 \mathrm{H}_{2} \mathrm{O}, \mathrm{CaCl}_{2} \cdot 2 \mathrm{H}_{2} \mathrm{O}$, ferric citrate, citric acid, $\mathrm{H}_{3} \mathrm{BO}_{3}, \quad \mathrm{MnCl}_{2}, \quad \mathrm{CuSO}_{4} \cdot 5 \mathrm{H}_{2} \mathrm{O}, \quad \mathrm{CoCl}_{2}, \mathrm{Na}_{2} \mathrm{MoO}_{4}$, $\mathrm{ZnSO}_{4} \cdot 7 \mathrm{H}_{2} \mathrm{O}$, and $\mathrm{H}_{2} \mathrm{SO}_{4} 0,072 \mathrm{~N}$, in accordance with. $\frac{15}{5}$ Batch cultures in glass bottles were inoculated with $25 \%$ inoculum incubated under 5,200 lux light intensity for $16 / 8$ hours (light/dark) at $25^{\circ} \mathrm{C}$ and aerated with $1.5 \mathrm{~L}$ ambient air per minute. The cultures were incubated until they reached the stationary phase. The $\mathrm{pH}$ of the cultures was adjusted to $7.00 \pm 0.5$ and maintained the same until the harvest time. There was four variations of nitrogen $(\mathrm{N})$ concentration applied to this research i.e. 5, 28, 55 (control), and $350 \mathrm{mg} \mathrm{N} \mathrm{L}^{-1}$. The design of the experiment was a completely randomized design (CRD) with 5 replicates for each treatment; therefore 20 bottles of culture were prepared.

\subsection{Growth and Biomass Productivity}

Samples of Botryococcus sp. culture were harvested daily for optical density (OD) measurement by spectrophotometer at $\lambda=680 \mathrm{~nm}$. Botryococcus sp. biomass was determined 
from the linear equation (equation 1) which obtained from the standard curve between OD and cell density of Botryococcus sp growth, according to the method described by. $\underline{16}$

$$
y=2.49 x
$$

with:

$y$ is the optical density

$x$ is the cell density or biomass

The specific growth rate $(\mu)$ of the culture was calculated based on equation 2 .

$$
\mu=\frac{\ln x_{t}-\ln x_{0}}{t-t_{0}}
$$

with:

$\mu$ is specific growth rate $\left(\right.$ day $\left.^{-1}\right)$

$x_{t}$ is biomass at time $\mathrm{t}(\mathrm{g})$

$x_{0}$ is initial biomass $(\mathrm{g})$

$t$ is the end of the exponential phase (day)

$t_{0}$ is the beginning of the exponential phase (day)

The productivity of biomass was calculated based on equation 3:

$$
P=\frac{X t-X o}{t-t o}
$$

With $P$ is the productivity of biomass $\left(\mathrm{mg} \mathrm{L}^{-1}\right.$ day $\left.^{-1}\right)$ $x_{t}$ is biomass at time $\mathrm{t}(\mathrm{mg})$

$x_{0}$ is initial biomass $(\mathrm{mg})$

$t$ is the end of culture (day)

\subsection{Nitrogen Consumption}

Nitrogen consumption was determined based on the level of nitrate in the medium during cultivation. For the determination of nitrate concentration in the culture medium, $5 \mathrm{ml}$ algae culture was centrifuged to separate the medium from the algal biomass. Nitrate concentration was determined using a spectrophotometric method described by. $\frac{17}{}$ Optical density of nitrate was measured at $\lambda 220 \mathrm{~nm}$ and $275 \mathrm{~nm}$. The optical density value was then converted into nitrate concentration data using a standard curve of nitrate concentration from 0 to $10 \mathrm{mg} \mathrm{L}^{-1}$.

\subsection{Harvesting and Oil Extraction}

The cultures of Botryococcus sp. were harvested every day by precipitating the cells with $3.0 \mathrm{M} \mathrm{NaOH}$ according to the method described by, $\underline{\underline{18}}$ filtered with double filter papers, and dried in an oven at $80^{\circ} \mathrm{C}$ until a constant weight was obtained. $\underline{19}$ Oil was extracted from the dried biomass in a Soxhlet extractor with $250 \mathrm{ml} \mathrm{n}$-hexane for 4 hours at $70^{\circ} \mathrm{C}$. The extracted oil hydrocarbon was separated from the solvent using a vacuum rotary evaporator and placed in a vial for weighing. Oil hydrocarbon concentration was calculated with equation 4 .

$$
\text { Oilhydrocarbon }(\%)=\frac{\text { hydrocarbonextracted }}{\text { biomassdryweight }} \times 100 \%
$$

\subsection{Analysis of Fatty Acid}

The composition of fatty acids in Botryococcus sp. oil was analyzed using gas chromatography. Prior to the analysis, the oil was transmethylated into fatty acid methyl esters (FAME) by adding $10 \mathrm{ml}$ sodium hydroxide in $0.2 \mathrm{~N}$ methanols to $0.25 \mathrm{~g}$ oil, followed by refluxing for 15 minutes until the color turned clear? The temperature of the mixture was cooled to room temperature, and then 2 drops of phenolphthalein were added. A solution of $1 \mathrm{~N}$ $\mathrm{H}_{2} \mathrm{SO}_{4}$ in methanol was added to the mixture until the color of the mixture vanished. It was then heated back for 20 minutes then cooled down to room temperature. Saturated $\mathrm{NaCl}(20 \mathrm{ml})$ was added to the mixture and stirred well until homogeneous.

The mixture was transferred into a $50 \mathrm{ml}$ volumetric flask then $5 \mathrm{ml}$ of heptanes was added to the mixture and homogenized until it formed two layers. A more saturated $\mathrm{NaCl}$ solution was added to the mixture to elevate the upper layer so that the pipette could reach it. The upper layer of the mixture consists of fatty acid methyl ester which was subsequently injected into gas chromatography (GC). A correction factor $\left(\mathrm{K}_{\mathrm{i}}\right)$ was calculated according to equation 5 .

$$
K_{i}=\left(\frac{\text { standard'sarea }}{\sum \text { standards'areas }}\right) \times\left(\frac{\sum \% \text { components }}{\% \text { component }}\right)
$$

\section{Results and Discussion}

\subsection{Growth of Botryococcus sp.}

Under the microscope, the Botryococcus sp. cells were seen as green single cells (Figure 1). The cells of Botryococcus sp. grew well in glass bottles under 5,200 lux light intensity for $16 / 8$ hours (light/dark) at $25^{\circ} \mathrm{C}$ and aerated with $1.5 \mathrm{~L}$ ambient air per minute. 

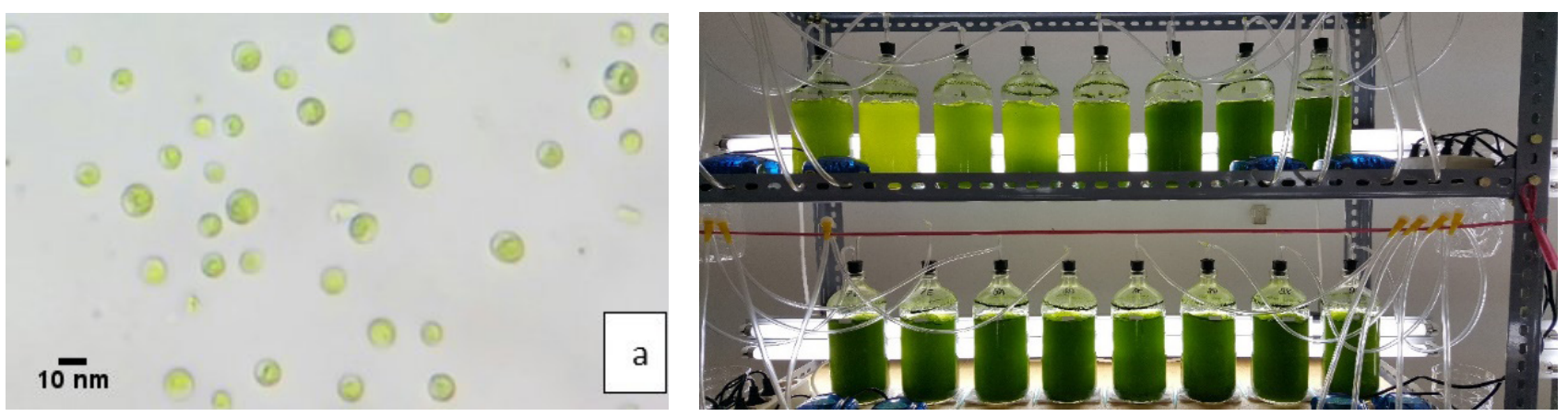

Figure 1. a) Microscopic Botryococcus sp., b) Culture of Botryococcus sp. in glass bottle.

Based on equation 1, the algal biomass $\left(\mathrm{g} \mathrm{L}^{-1}\right)$ for each day was determined. From the biomass data plotted to time (days), the algal growth curve could be drawn (Figure 2), which showed that the growth curves of each culture consisted of lag phase, exponential phase, linear phase and stationary phase. In this experiment, it could be seen that the algal growth was affected by the concentration of nitrogen in the culture media. The highest biomass growth was achieved by culture with an initial nitrogen concentration of $350 \mathrm{mg} \mathrm{L}^{-1}$, followed by the culture with the initial nitrogen concentrations of $55 \mathrm{mg} \mathrm{L}^{-1}, 28 \mathrm{mg} \mathrm{L}^{-1}$, and $5 \mathrm{mg} \mathrm{L}^{-1}$ respectively (Figure 2). The growth of Botryococcus sp. in the medium with
$5 \mathrm{mg} \mathrm{L}^{-1}$ nitrogen was lower compared to the growth in the normal concentration of nitrogen, $55 \mathrm{mg} \mathrm{L}^{-1}$. This indicated that the higher the nitrogen concentration in the medium, the higher was the growth of Botryococcus sp. On the other hand, in nitrogen deficiency conditions the growth of Botryococcus sp. decreased significantly. Thus nitrogen concentration was a limiting factor for the growth of Botryococcus sp.

The specific growth rate $(\mu)$ was found to increase along with the increased nitrogen concentration. The highest specific growth rate $(\mu)$ of the culture was found in the culture media with $350 \mathrm{mg} \mathrm{N} \mathrm{L}^{-1}$ i.e. $0.24 \mathrm{~g} \mathrm{day}^{-1}$, and the lowest $\mu$ was in the culture media with $5 \mathrm{mg} \mathrm{N} \mathrm{L}^{-1}$ i.e. 0.12

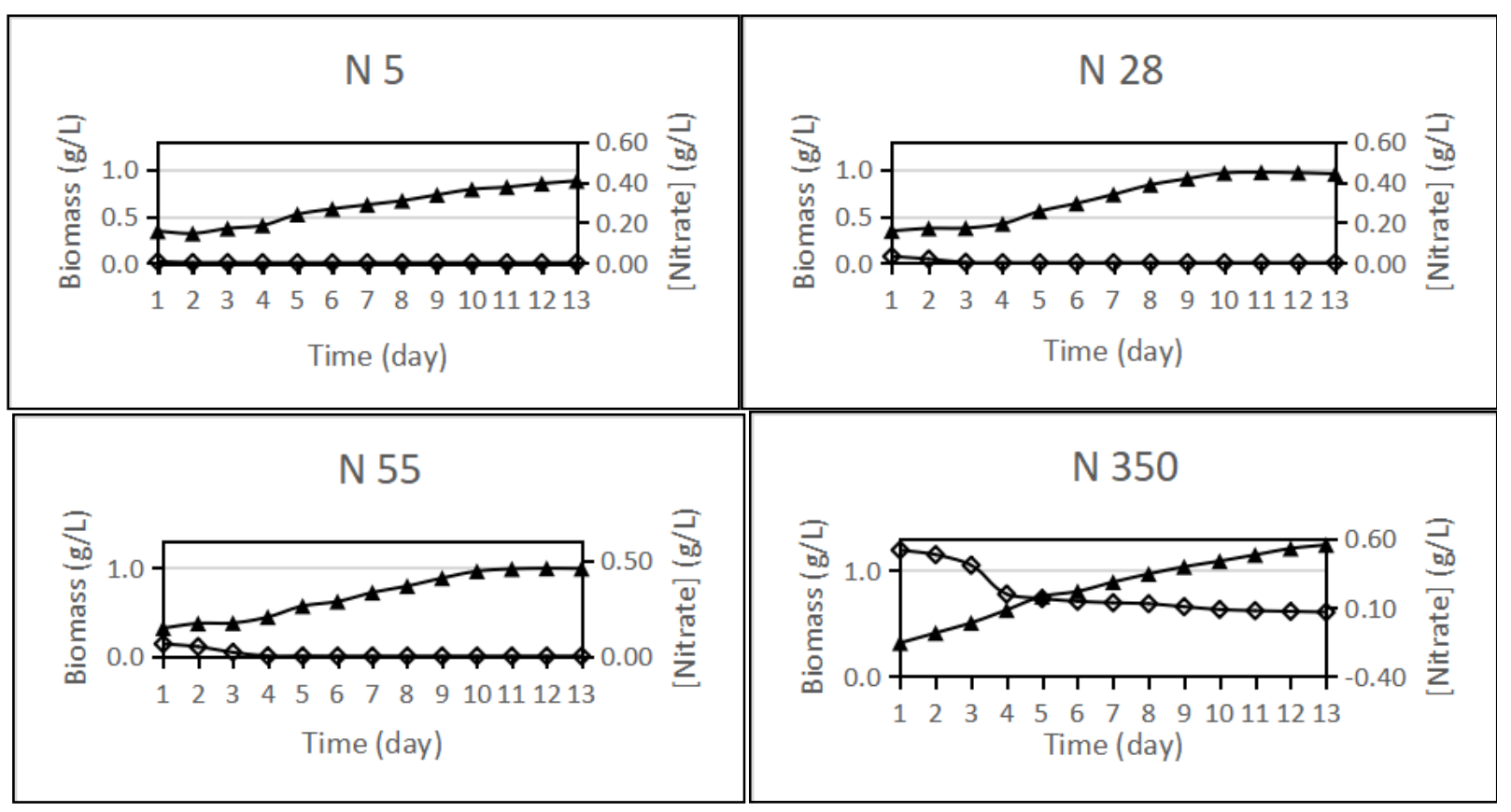

Figure 2. Growth curve and level of nitrate in culture media of Botryococcus sp. under different concentrations of nitrogen, of 5, 28, 55, $350 \mathrm{mg} \mathrm{L}^{-1}$ ( $\mathbf{\Lambda}$ : biomass growth; $\diamond$ : nitrate level). 
$\mathrm{g} \mathrm{day}^{-1}$. The specific growth rates in the culture media with $28 \mathrm{mg} \mathrm{N} \mathrm{L}^{-1}$ and $55 \mathrm{mg} \mathrm{N} \mathrm{L}^{-1}$ were not significantly different i.e. $0.19 \mathrm{~g} \mathrm{day}^{-1}$ and $0.20 \mathrm{~g} \mathrm{day}^{-1}$, respectively. This indicates that high initial nitrogen concentration could accelerate the growth rate of Botryococcus sp., the higher the nitrogen concentration in the medium the higher were the growth rate $(\mu)$. The $\mu$ in culture with $55 \mathrm{mg} \mathrm{N} \mathrm{L}^{-1}$ was $0.20 \mathrm{~g} \mathrm{day}^{-1}$ which was higher than. ${ }^{20}$ Experiment which was only $0.033 \mathrm{~g}^{\text {day }}{ }^{-1}$, who used Botryococcus sp. UTEX 572 with $51 \mathrm{mg} \mathrm{N} \mathrm{L}^{-1}$, but almost the same with that of Choi, et al.experiment ${ }^{21}$ which was $0.185 \mathrm{~g} \mathrm{day}^{-1}$, who used Botryococcus sp. UTEX 572 with $3.66 \mathrm{mM}$ nitrate $\left(51.24 \mathrm{mg} \mathrm{N} \mathrm{L}^{-1}\right) . \underline{21}$

\subsection{Nitrogen Consumption}

The nitrogen consumption by algal cultures was different between the cultures (Figure 2). It could be seen that the concentration of nitrogen in each medium decreased along with the growth of biomass. This indicated that the nitrogen was consumed by the algae for growth. In a medium with an initial nitrogen concentration of $5.0 \mathrm{mg} \mathrm{L}^{-1}$ the entire nitrogen (100\%) was consumed by day- 2 . This was followed by an increase in biomass until day-12 and then the culture entered the stationary phase. Consumption of nitrogen in the media with initial nitrogen concentrations of 28.0 and $55.0 \mathrm{mg} \mathrm{L}^{-1}$ was 99.51 and $99.55 \%$, respectively, by day- 4 . This indicated that almost the entire nitrogen in the media with initial concentrations of 5,28 , and $55 \mathrm{mg} \mathrm{N} \mathrm{L}^{-1}$ was consumed. Meanwhile, in the medium with an initial nitrogen concentration of $350 \mathrm{mg} \mathrm{L}^{-1}$, only $47.86 \%$ of nitrogen was consumed, as seen that the level of nitrogen on day-10 onwards was relatively constant. These results indicated that initial nitrogen concentrations of 5.0, 28.0 and $55.0 \mathrm{mg} \mathrm{L}^{-1}$ in the culture media were highly efficient, while $350 \mathrm{mg} \mathrm{N} \mathrm{L}^{-1}$ was not efficient as indicated by the high remaining nitrogen in the medium at the end of cultivation.

\subsection{Oil Content}

In this study, the highest intracellular oil content was obtained from cultures with an initial nitrogen concentration of $5 \mathrm{mg} \mathrm{L} \mathrm{L}^{-1}$, followed consecutively with initial nitrogen concentrations of 55 and $28 \mathrm{mg}$ $\mathrm{L}^{-1}$ (Figure 3). The lowest oil content was obtained in culture with an initial nitrogen concentration of 350

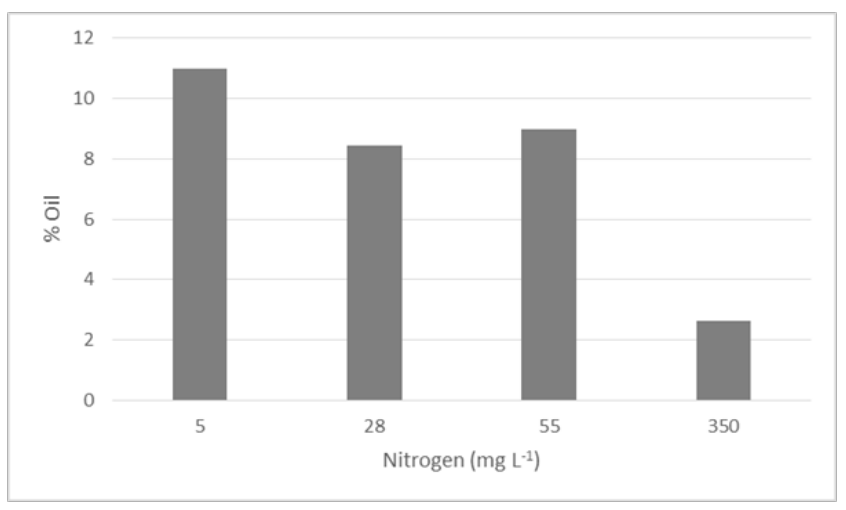

Figure 3. Oil percentage in cultivated Botryococcus sp. with nitrogen concentrations of 5, 28, 55, $350 \mathrm{mg} \mathrm{L}^{-1}$.

mg L ${ }^{-1}$ which showed the best growth with the highest biomass accumulation. Cultures with initial nitrogen 5.0 $\mathrm{mg} \mathrm{L}^{-1}$ showed lower biomass accumulation compared to cultures with initial nitrogen concentrations of 28.0, $55.0,350.0 \mathrm{mg} \mathrm{L}^{-1}$. However, the culture with an initial nitrogen of $5.0 \mathrm{mg} \mathrm{L}^{-1}$ had higher oil content. Based on these results, there was a negative correlation between biomass growth and oil accumulation.

The increased oil hydrocarbon accumulation that occurred at low nitrogen concentrations could be caused by the transfer of metabolic pathways from biomass formation to oil hydrocarbon formation. The form of accumulated oil hydrocarbon is uncharged hydrocarbons, especially TAG. The formation of TAG begins with the formation of fatty acids (FA). FA is formed through the de novo pathway in chloroplasts with acetyl-Coenzyme A (acetyl-CoA) as a substrate. Acetyl-CoA is converted to malonyl-CoA which is catalyzed by acetyl-CoA carboxylase (ACCase). Malonil-CoA then enters the process of elongation of fatty acids to be formed into various fatty acids which are catalyzed by multisubunit enzymes, namely fatty acid synthase (FAS).

The FA is then hydrolyzed to form free fatty acids (FFA) which are transferred to glycerol-3-phosphate (G3P) and followed by the formation of lysophosphatidic acid (LysoPA). LysoPA is then converted into phosphatidic acid (PA), which is converted to diacylglycerol (DAG), and finally triacylglycerol (TAG). The formation of TAG from DAG can be through two pathways, namely the direct glycerol pathway (Kennedy pathway) or the independent acyl-CoA pathway. On the Kennedy pathway, fatty acids are transferred from acyl-ACP by diacylglycerol acyltransferase (DGAT). On an independent acyl-CoA 
pathway, fatty acyl for the formation of TAG is obtained from hydrocarbon membranes. $\underline{22}, \underline{23}$

Atlownitrogen conditions, levels of glycerohydrocarbon membranes are known to decrease while TAG levels increase. The increase in TAG was caused by an increase in DGAT activity which catalyzes the change in DAG to TAG. Increased activity also occurred in the phosphohydrocarbon diacylglycerol acyltransferase (PDAT) enzyme and several lipase enzymes that catalyze the reuse of FA from hydrocarbon membranes. Pyruvate levels also increase with increasing G3P changes to pyruvate and pyruvate synthesis from malate. Increases also occur in the TCA cycle, with more substrate for FA production and FA reuse of hydrocarbon membranes, the formation of TAG is more so that the oil hydrocarbon content increases. $\underline{24}$

Hydrocarbon oil levels obtained in this study were in the range of $2.65 \%-11.0 \%$ of biomass dry weight. In a study conducted by, $\underline{25}$ the levels of hydrocarbons in Botryococcus sp. strains SK, TRG, PSU, and KB were 15.8; 25.8; 5.7; and $17.8 \%$ in Chu-13 medium. .25 Hydrocarbon level in Botryococcus sp. Showa strain was $30-39 \%, \underline{26}$ in KMITL 2 strain was $12-55 \%, \underline{27}$ and in the Göttingen strain, $807 / 1$ was $44 \%$. $\underline{28}$ In the UK $807-2$ strain used by $\underline{29}$ the hydrocarbon content was nearly $80 \% \underline{\underline{29}}$

In general, oil level obtained in Botryococcus sp. under this study was lower than the level of oil obtained in other studies. There were several reasons that might cause these results: (1) the Botryococcus sp. strain used in this study did not have the capability to produce high levels of hydrocarbons; (2) the initial nitrogen concentration given did not give rise to nitrogen-deficient culture conditions, but only limitations; or (3) there were culture conditions other than nitrogen concentration which did not match the strain used in this study.

\subsection{The productivity of Biomass and Algal Oil}

The biomass productivity was increased as the nitrogen concentration increased. The highest productivity was obtained in the medium with $350 \mathrm{mg} \mathrm{N} \mathrm{L}^{-1}$, followed by $55 \mathrm{mg} \mathrm{N} \mathrm{L}^{-1}, 28 \mathrm{mg} \mathrm{N} \mathrm{L}^{-1}, 5 \mathrm{mg} \mathrm{N} \mathrm{L}^{-1}$, which were 77.5, 57.3, 54.5 and $48.2 \mathrm{mg} \mathrm{L}^{-1}$ day $^{-1}$, respectively (Figure 4.) On the other hand, the algal oil productivity was not positively correlated with the concentration of nitrogen. The highest oil productivity as much as $5.03 \mathrm{mg}$ oil L $\mathrm{L}^{-1} \mathrm{~d}^{-1}$ was obtained in the medium with $55 \mathrm{mg} \mathrm{N} \mathrm{L}^{-1}$, followed by the medium with $5 \mathrm{mg} \mathrm{N} \mathrm{L}^{-1}, 28 \mathrm{mg} \mathrm{N} \mathrm{L}^{-1}$ i.e. 4.96 and $4.3 \mathrm{mg}$ oil L $\mathrm{L}^{-1} \mathrm{~d}^{-1}$, respectively. The lowest oil productivity was $2.04 \mathrm{mg}^{\circ}$ oil $\mathrm{L}^{-1} \mathrm{~d}^{-1}$ in the medium with $350 \mathrm{mg} \mathrm{N}$ $\mathrm{L}^{-1}$ (Figure 4.). These results indicate that the optimal nitrogen for oil production was $55 \mathrm{mg} \mathrm{N} \mathrm{L}^{-1}$ and the optimal nitrogen concentration for biomass production was $350 \mathrm{mg} \mathrm{N} \mathrm{L}^{-1}$.

\subsection{Fatty Acid Composition}

The fatty acid composition of oil extracted from the Botryococcus sp. culture with $5 \mathrm{mg} \mathrm{N} \mathrm{L}-1,28 \mathrm{mg} \mathrm{N}$ $\mathrm{L}^{-1}, 55 \mathrm{mg} \mathrm{N} \mathrm{L} \mathrm{L}^{-1}$ was dominated by palmitic acid with concentrations of $38.07 \%, 35.59 \%$ and $29.48 \%$, respectively (Table 1). The difference in fatty acid dominance was only seen in cultures with $350 \mathrm{mg} \mathrm{N}$ $\mathrm{L}^{-1}$ which contained $22.51 \%$ decanoic acid, followed by $19.43 \%$ palmitic acid. High production of palmitic acid was needed as a substrate for glycerol to hydrocarbon metabolism, glycerophosphate hydrocarbon metabolism, and elongation of fatty acids in the form of acyl-CoA, namely palmitoyl-CoA. The dominance of palmitic acid was also thought to be due to a decrease in the activity of the long-chain acyl-CoA synthase enzyme needed to convert palmitic acid to palmitoyl-CoA.

Oleic acid was the second-largest oil component in Botryococcus sp. culture with $5 \mathrm{mg} \mathrm{N} \mathrm{L}{ }^{-1}, 28 \mathrm{mg} \mathrm{N} \mathrm{L}^{-1}$, $55 \mathrm{mg} \mathrm{N} \mathrm{L}^{-1}$. The oleic acid concentration increases with increasing initial nitrogen concentration given, except in cultures with $350 \mathrm{mg} \mathrm{N} \mathrm{L}^{-1}$. These results were different from the results obtained by Choi, et al. .11 where the concentration of oleic acid was increased in Botryococcus braunii UTEX572 cultures given low nitrogen concentrations, which was caused by an increase in the



Figure 4. Biomass and oil productivity of Botryococcus sp. with nitrogen concentrations of $5,28,55,350 \mathrm{mg} \mathrm{L}^{-1}$. 
Table 1. Fatty acid relative percentages to total fatty acid methyl ester (FAME)

\begin{tabular}{|c|c|c|c|c|c|}
\hline \multirow{2}{*}{\multicolumn{2}{|c|}{ Fatty acid }} & \multicolumn{4}{|c|}{ Fatty acid (\%) of extracted oil } \\
\hline & & \multirow{2}{*}{$\frac{5 \mathrm{mg} \mathrm{NL}^{-1}}{6.65}$} & \multirow{2}{*}{$\frac{28 \mathrm{mg} \mathrm{NL}^{-1}}{3.69}$} & \multirow{2}{*}{$\frac{55 \mathrm{mg} \mathrm{NL}^{-1}}{0}$} & \multirow{2}{*}{$\frac{350 \mathrm{mg} \mathrm{NL}^{-1}}{22.51}$} \\
\hline Decanoic & C10:0 & & & & \\
\hline Lauric & C12:0 & 0.83 & 2.61 & 1.94 & 2.08 \\
\hline Myristic & C14:0 & 0.91 & 2.9 & 4.29 & 1.66 \\
\hline Palmitic & C16:0 & 38.07 & 34.59 & 29.48 & 19.43 \\
\hline Stearic & C18:0 & 8.4 & 6.87 & 9.05 & 1.95 \\
\hline Palmitoleic & $\mathrm{C} 16: 1$ & 1.44 & 0 & 5.43 & 0 \\
\hline Elaidic & $\mathrm{C} 18: \ln 9 \mathrm{t}$ & 0.52 & 0 & 0 & 1.41 \\
\hline Oleic & C18:1n9c/18:1 & 22.29 & 24.52 & 26.99 & 8.81 \\
\hline Linoleic cc & $\mathrm{C} 18: 2 \mathrm{n} 6 \mathrm{cc}$ & 6.69 & 15.05 & 11.54 & 10.7 \\
\hline Alfa Linolenic ccc & $\mathrm{C} 18 \mathrm{~s} 3 \mathrm{n} 3 \mathrm{ccc}$ & 1.3 & 0 & 0 & 0 \\
\hline Gamma Linolenic ccc & $\mathrm{C} 18: 3 \mathrm{n} 6 \mathrm{ccc}$ & 1.34 & 0 & 3.86 & 16.11 \\
\hline Eicosenoic & C20:1n9 & 4.19 & 7.91 & 5.7 & 14.19 \\
\hline DHA & $\mathrm{C} 22: 6 \mathrm{n} 3$ & 0.09 & 1.86 & 1.71 & 1.15 \\
\hline
\end{tabular}

Bold value indicates the dominant types of fatty acids with the number of carbon atom and percentage of fatty acids.

stearoyl-ACP desaturase (SAD) enzyme which plays a role in the process of oleic acid synthesis. $\underline{30}$ However, the results of this study were in accordance with the study of 27 and $\underline{31}$ where the culture of Botryococcus braunii Kutz IPPAS H-252 on Prate medium with nitrogen-deficient conditions contained lower oleic acid concentrations than controls. $\underline{31}$

The fatty acid composition which was predominated by palmitic acid compared to oleic acid was thought to be caused by the form of nitrogen source added. According to 27 the administration of nitrogen sources in the form of $\mathrm{KNO}_{3}$ and $\mathrm{NaNO}_{3}$ triggers Botryococcus braunii to produce $\mathrm{C} 16: 0$ more than the administration of nitrogen in other forms. On the other hand, C17:0 and C18:0 are produced higher in cultures provided with nitrogen in the form of $\mathrm{Co}\left(\mathrm{NH}_{2}\right)_{2}$ and $\mathrm{NH}_{4} \mathrm{HCO}_{3}$. In general, nitrogen deficiency conditions in this study could increase the saturated fatty acids. Similar results were reported by 27 and $\frac{31}{}$.

The fatty acid composition influences the characteristics of biodiesel, specifically the cetane number, acid number, saponification number, $\underline{32}$ and iodine number. In this study, the range of fatty acid composition in each treatment was $44.7-58.5 \%$ saturated fatty acids, monounsaturated fatty acids $28.4-38.8 \%$, and polyunsaturated fatty acids $13-28 \%$. Based on research conducted by, $\underline{33}$ crude oil with a composition of saturated fatty acids $20-100 \%$, monounsaturated fatty acids $0-80 \%$, and polyunsaturated fatty acids $0-30 \%$ can be processed into biodiesel with a cetane and iodine numbers that meet European standards UNE-EN 14214. $\underline{33}$

\section{Conclusion}

The concentration of nitrogen in the culture medium of Botryococcus sp. influenced growth, the productivity of biomass, the productivity of algal oil, and the composition of fatty acids. The higher the concentration of nitrogen in the culture medium the higher was the growth rate and biomass productivity as indicated by the maximal growth rate and biomass productivity of Botryococcus sp. in medium containing $350 \mathrm{mg} \mathrm{N} \mathrm{L}^{-1}$ i.e. $0.24 \mathrm{~g}_{\text {day }}{ }^{-1}$ and $77.5 \mathrm{mg} \mathrm{L}^{-1}$ day $^{-1}$ respectively. However, maximal oil productivity was obtained in medium containing less nitrogen i.e. $55 \mathrm{mg} \mathrm{N} \mathrm{L}^{-1}$, with oil productivity of $5.03 \pm$ $0.10 \mathrm{mg} \mathrm{L}^{-1} \mathrm{~d}^{-1}$. Highly efficient nitrogen consumption was obtained from cultures grown in media containing low nitrogen concentration $\left(5.0,28.0,55.0 \mathrm{mg} \mathrm{L}^{-1}\right)$, whereas cultures grown in media containing high nitrogen (350 $\mathrm{mg} \mathrm{N} \mathrm{L}{ }^{-1}$ ) were less efficient.

From the results of nitrogen consumption associated with oil productivity, it could be concluded that the 
addition of nitrogen to a final concentration of 55.0 mg L-1 was the most efficient in producing the highest algal oil productivity. The fatty acid composition was also influenced by nitrogen concentration, which was mostly dominated by palmitic acid (saturated fatty acid) and oleic acid (unsaturated fatty acid) in initial nitrogen concentrations of 5.0, 28.0, $55.0 \mathrm{mg} \mathrm{N} \mathrm{L}^{-1}$, but $350 \mathrm{mg} \mathrm{N}$ $\mathrm{L}^{-1}$ resulted in more decanoic acid. From the fatty acids composition, it was shown that oil hydrocarbon from Botryococcus sp. fulfilled the requirements to be processed into biodiesel.

\section{Acknowledgements}

This research project was funded by the Program of Research, Community Services and Innovation (P3MI), Institut Teknologi Bandung, Indonesia, 2017.

\section{References}

1. Sharif ABMH, Nasrulhaq AB, Majid HAM, Chandran S, Zuliana R. Biodiesel production from waste cooking oil as environmental benefits and recycling process. A review. In: Asia biofuel conference book; 2007. P. 11-13.

2. Aresta M, Dibenedetto A, Barberiio G. Utilization of macroalgae for enhanced $\mathrm{CO}_{2}$ fixation and biofuels production: development of computing software for an LCA study. Fuel Process Technol. 2005;86(14-15):1679-93.

3. Hossain ABMS, Salleh A, Boyce AN, Chowdhury P, Naqiuddin M. Biodiesel fuel production from algae as renewable energy. Am J Biochem Biotechnol. 2008;4(3):250-54.

4. Banerjee A, Sharma R, Christi Y, Banerjee UC. Botryococcus braunii: a renewable source of hydrocarbons and other chemicals. Crit Rev Biotechnol. 2002;22(3):245-79.

5. Meng X, Yang J, Xu X, Zhang L, Nie Q, Xian M. Biodiesel production from oleaginous microorganisms. Renew Energy. 2009;34(1):1-5.

6. Tran HL, Kwon JS, Kim ZH, Oh Y, Lee CG. Statistical optimization of culture media for growth and lipid production of Botryococcus braunii LB572. Biotechnol Bioprocess Eng. 2010;15(2):277-84.

7. Zhila N, Kalacheva G, Volova T, Degermendzhi A. Structure of hydrocarbons synthesized by the alga Botryococcus isolated from Lake Shira. Dokl Biol Sci. 2001;378:265-9.

8. Brennan L, Owende P. Biofuels from microalgae-a review of technologies for production, processing, and extractions of biofuels and co-products. Renew Sustain Energy Rev. 2010;14(2):557-77.
9. Scott SA, Davey MP, Dennis JS, Horst I, Howe CJ, Lea-Smith DJ, et al. Biodiesel from algae: challenges and prospects. Curr Opin Biotechnol. 2010;21(3):277-86.

10. Wijihastuti R S. Growth and photosynthetic activity of Botryococcus braunii biofilm. J Appl Phycol. 2017;29(3):1123-34.

11. Handbook of marine microalgae: biotechnology advances. [cited 2015]. https://www.sciencedirect.com/ book/9780128007761/handbook-of-marine-microalgae.

12. Procházková G, Brányiková I, Zachleder V, Brányik T. Effect of nutrient supply status on biomass composition of eukaryotic green microalgae. J Appl Psychol. 2014;26(3):1359-77.

13. Cheng P, Wang J, Liu T. Effects of nitrogen source and nitrogen supply model on the growth and hydrocarbon accumulation of immobilized biofilm cultivation of Botryococcus sp. Bioresour Technol. 2014;166:527-33.

14. Goncalves EC, Wilkie AC, Kirst M, Rathinasabapathi B. Metabolic regulation of triacylglycerol accumulation in the green algae: identification of potential targets for engineering to improve oil yield. Plant Biotechnol J. 2016;14(8):1649-60.

15. Yamaguchi K, Nakano H, Murakami M, Konosu S, Nakayama O, Kanda M, et al. Lipid composition of a green alga, Botryococcus braunii. Agric Biol Chem. 1987;51(2):493-8.

16. Yu WL, Ansari W, Schoepp NG, Hannon MJ, Mayfield SP, Burkart MD. Modifications of the metabolic pathways of lipid and triacylglycerol production in microalgae. Microb Cell Fact. 2011;10(1):91.

17. Ho SH, Chen CY, Chang JS. Effect of light intensity and nitrogen starvation on CO2 fixation and lipid/carbohydrate production of an indigenous microalgae Scenedesmus obliquus CNW-N. Bioresour Technol. 2012;113:244-52.

18. Kim L, Kwon K, Oh Y. Effects of harvesting method and growth stage on the flocculation of the green alga Botryococcus braunii. Lett Appl Microbiol. 1998;27(1):14-18.

19. Bagchi SK, Rao PS, Mallick N. Development of an oven drying protocol to improve biodiesel production for an indigenous chlorophycean microalga Scenedesmus sp. Bioresour Technol. 2015;180:207-13.

20. An JY, Sim SJ, Lee JS, Kim BW. Hydrocarbon production from secondarily treated piggery wastewater by the green alga Botryococcus braunii. J Appl Phycol. 2003;15(2):185-91.

21. Choi GG, Kim BH, Ahn CY, Oh HM. Effect of nitrogen limitation on oleic acid biosynthesis in Botryococcus braunii. J Appl Phycol. 2010;23(6):1031-7.

22. Cagliari A, Margis R, Dos Santos Maraschin F, TurchettoZolet AC, Loss G, Margis-Pinheiro M. Biosynthesis of triacylglycerols (TAGs) in plants and algae. Int J Plant Biol. 2011;2(1):10. 
23. Klok A, Lamers P, Martens D, Draaisma R, Wijffels R. Edible oils from microalgae: insights in TAG accumulation. Trends Biotechnol. 2014;32(10):521-8.

24. Li J, Han D, Wang D, Ning K, Jia J, Wei L, Xu J. Choreography of transcriptomes and lipidomes of 24. nannochloropsis reveals the mechanisms of oil synthesis in microalgae. Plant Cell. 2014;26(4):1645-65.

25. Yeesang C, Cheirsilp B. Effect of nitrogen, salt, and iron content in the growth medium and light intensity on lipid production by microalgae isolated from freshwater sources in Thailand. Bioresour Technol. 2011;102(3):3034-40.

26. Yoshimura T, Okada S, Honda M. Culture of the hydrocarbon producing microalga Botryococcus braunii strain Showa: optimal $\mathrm{CO}_{2}$, salinity, temperature, and irradiance conditions. Bioresour Technol. 2013;133:232-9.

27. Ruangsomboon S. Effect of light, nutrient, cultivation time and salinity on lipid production of newly isolated strain of the green microalga, Botryococcus braunii KMITL 2. Bioresour Technol. 2012;109:261-5.

28. Casadevall E, Dif D, Largeau C, Gudin C, Chaumont D, Desanti O. Studies on batch and continuous cultures of
Botryococcus braunii: hydrocarbon production in relation to physiological state, cell ultrastructure, and phosphate nutrition. Biotechnol Bioeng. 1985;27(3):286-95.

29. Li Y, Qin JG. Comparison of growth and lipid content in three Botryococcus braunii strains. J Appl Phycol. 2005;17(6):551-6.

30. Choi GG, Kim BH, Ahn CY, Oh HM. Effect of nitrogen limitation on oleic acid biosynthesis in Botryococcus braunii. J Appl Phycol. 2010;23(6):1031-7.

31. Zhila NO, Kalacheva GS, Volova TG. Influence of nitrogen deficiency on biochemical composition of the green alga Botryococcus. J Appl Phycol. 2005;17(4):309-15.

32. Lei A, Chen H, Shen G, Hu Z, Chen L, Wang J. Expression of fatty acid synthesis genes and fatty acid accumulation in Haematococcus pluvialis under different stressors. Biotechnol Biofuels. 2012;5(1):18.

33. Ramos MJ, Fernández CM, Casas A, Rodríguez L, Pérez Á. Influence of fatty acid composition of raw materials on biodiesel properties. Bioresour Technol. 2009;100(1):261-8. 